Volume-V, Issue- 02, July-December, 2010

\title{
Problems and Prospects of SMEs Loan Management: A Study on Mercantile Bank Limited, Khulna Branch
}

\begin{abstract}
S. M. AKTERUJJAMAN ${ }^{1}$

SMEs all over the world have been playing a crucial role in promoting economic development as well as industrial production. SME financing has been identified as a major obstacle to SME growth. Unfortunately, the issue seems to be as unresolved as it always has been. Though the majority of the issues are with the SME themselves, the banks also have major issues in designing financial products for the SMEs. This study tries to find out the underlying problems from the bank's perspective. The major findings are related to the high interest and loan duration rates, reasons for SMEs relatively informal way of doing business in contrast to bank's formal procedures and prerequisites, bank's relative inexperience in this field. They are also related to the bank's lack of perspective, the viability and benefits of cluster unity, approach to informal loan takers and non-usage of modern technology and accounting procedures. The recommendations were provided based on the analysis and findings.
\end{abstract}

Key words: Small and Medium Enterprises (SMEs), Financing, Loan, Technology, Cluster.

\section{INTRODUCTION}

Small and medium enterprises (SMEs) all over the world have been playing a crucial role in promoting economic development as well as industrial production. In particular, SMEs provide the necessary foundations for sustained growth and rising income in the less developed and transitional economies. SME financing is a topic of significant research interest to academics and an issue of great importance to the policymakers of Bangladesh and around the world. Economic as well as technical and social arguments warrant the promotion of SMEs as they create large scale, low-cost employment opportunities, use locally available inputs and technologies, mobilize small and scattered private savings, develop entrepreneurship, and correct the regional imbalance in development that exists in developing countries. Despite

\footnotetext{
${ }^{1}$ Senior Lecturer, Department of Business Administration, Northern University Bangladesh, E-mail: smakter2010@gmail.com
} 
all these potentials, SMEs are disappearing, abandoning the potential role they could have played in economic development. Several studies have identified the major obstacles that include, but not limited to financing, infrastructure facilities, taxes and regulations, and stability in policies. Access to financing continues to be one of the most significant challenges for the growth and survival of SMEs especially innovative ones.

This paper focuses on the financial constraints that SMEs face in Bangladesh. In Bangladesh, commercial banks are not interested to finance SMEs because of the high risk and high supervision cost associated with this type of financing. Absence of sound collateral puts SMEs at a relative disadvantage. However, this study has found that some of the commercial banks have some "innovative" products or services targeting at SMEs only, while others have "repackaged" some of their existing products as SME products. It is generally recognized that SMEs have a significant role in employment generation, poverty reduction and overall economic growth, especially for a developing economy like Bangladesh. SMEs are typically labor-intensive industries with relatively low capital intensity. As such, for a country like Bangladesh, which is labor abundant and capital scarce, SMEs have a natural comparative advantage.

\subsection{Objectives of the Study}

The main objective of the study is to find out the major problems and prospects of SME loan management of Mercantile Bank Ltd., Khulna Branch. However, the specific objectives are as follows:

1. To find out the bank's reasons for reluctance to providing loans to the SMEs.

2. To find out the banks problems and prospects in designing proper financial products for the SMEs.

3. To suggest recommendations to overcome the problems related to SME loan management.

\section{LITERATURE REVIEW}

The Daily Star in its editorial (2006) mentioned that many SME owners are to face difficulties when they require bank loans. In fact, SME financing has recently been identified by experts as one of the major problems faced by SMEs in Bangladesh. 
Mahmud (2006) said that the SMEs have very limited bank finance, which is only around 10 percent, while self-finance remains the major source of their finance contributing 76.5 percent of fixed capital and 51.8 percent of working capital.

A World Bank survey (2002) on Bangladesh's SMEs identified lack of finance as the major issue, with 55\% SMEs reporting it. Bribes (21\%), orders/marketing of product $(28 \%)$, lack of knowledge $(12 \%)$, and license for work $(8 \%)$, along with new technology $(8 \%)$ were also considered as major issues. Without the much vital capital, they have little chance of growth or even sustenance in this mobile world. This study has tried to pinpoint, through empirical research, the major, problems faced by SMEs and banks in Bangladesh in relation to financing and has provided recommendations based on the findings to improve the situation.

Rosen (2003) mentioned that SMEs make up the largest portion of the employment base in many developing countries and, indeed, are often the foundation of the local private sector. The entrepreneurs behind them could and should play a much larger role in development, but too often are held back by a lack of ready access to financing from local formal sector financial institutions.

IFC (2004) Annual Review report mentioned that in almost every part of the world limited access to finance is one of the biggest obstacles to private sector growth. This is especially true for smaller firms that have minimum influence on policy reform.

Bhattacharya and Chowdhury (2003) mentioned that Bangladesh Bank encourages banks to give loans to projects for diversified industrial development. From the point of view of limiting the credit risk exposures of the banks having a higher level of classified loan, the new rule is justified. However, to consider large loans as risky loans (by the new rule) is not reasonable. Moreover, for increasing the volume of lending to the SME sector, this sort of supply-side policy is not adequate. In fact, under both directed lending (before 1990) and deregulated lending (after 1990) regimes, the demand-side factors were not considered; consequently, resource allocation suffered.

Hossain (1998) found that the most critical constraint that small and medium scale manufacturers mention is the lack of sufficient capital to operate the business. In most of the cases, businesses started using own savings and borrowing from friends and relatives, while banking source come after that. It is not so easy to rise fixed and working capital from banks, since banks are not so willing to provide loan of small size for high monitoring cost. On the other hand, potential small scale entrepreneurs are also not so much interested due to procedural hazards and requirement of long time, which may make the necessity of taking loan futile. Thus, the way to get bank loans needs to be simplified for the small entrepreneurs. 


\section{METHODOLOGY OF THE STUDY}

\subsection{Sources of Data}

This study is based on both primary and secondary data. Primary data were collected through personal interview with a structured questionnaire and direct observations. Fifty employees of Mercantile Bank Limited, Khulna Branch were used as the respondents and the sample units were drawn through convenience sampling method. Questionnaire was pre-tested and further improvement was done before conducting the survey. Respondents were assured of anonymity by asking them not to reveal their identity anywhere in the survey instrument. They were also told that neither their immediate supervisors nor their headquarters officials will have access to the individual questionnaire. Secondary data were collected from the published official statistics, reports documents, laws, ordinance, books, articles, periodicals of different domestic and international agencies, annual reports of concerned bank, different reports and statistics of Bangladesh Bank, Ministry of Finance, websites etc.

\subsection{Data Analysis Methods}

A five-point Likert type scale statements were used to measure the variables where 1 stands for strongly disagree/very low and 5 stands for strongly agree/very high effect on the statements. Multiple- item measures were developed for each psychological construct. After collection of primary data, hypotheses were formulated and Z-test is used to test the hypotheses with 0.05 level of statistical significance.

\subsection{Hypothesis Formulation}

Research hypothesis is an unproven statement, which helps the researcher to draw the suggestion on his hypothetical assumption whether it is true or false based on some specific statistical tests (Alam and Neger 2009). For this study, the following hypotheses (at 95\% confidence level) are developed, which are also to be tested.

\section{Hypothesis 1}

$\mathrm{H}_{0}$ : SMEs do not prepare proper financial statement.

$\mathrm{H}_{1}$ : SMEs prepare proper financial statement. 


\section{Hypothesis 2}

$\mathrm{H}_{0}$ : SMEs do not maintain proper licensing.

$\mathrm{H}_{1}$ : SMEs maintain proper licensing.

\section{Hypothesis 3}

$\mathrm{H}_{0}$ : Lack of upgraded technology affects SMEs ability to repay loans.

$\mathrm{H}_{1}$ : Lack of upgraded technology does not affect SMEs ability to repay loans.

\section{Hypothesis 4}

$\mathrm{H}_{0}$ : Mercantile Bank Limited grants large loan for the SMEs.

$\mathrm{H}_{1}$ : Mercantile Bank Limited does not grant large loan for the SMEs.

\section{Hypothesis 5}

$\mathrm{H}_{0}$ : Cost of operation for the bank will go down if the bank grants SME loan cluster wise.

$\mathrm{H}_{1}$ : Cost of operation for the bank will not go down if the bank grants SME loan cluster wise.

\section{DATA ANALYSIS}

An analysis is generated from the questionnaire to fulfill the objectives of the study. The number of respondents was 50 employees of Mercantile Bank Limited, Khulna Branch. From the responses of Bank's questionnaire, the researcher has taken the highly affecting responses and tries to find out the bank's problems in designing proper financial products for the SMEs. For the convenience of analysis the researcher has calculated the percentage of the responses. For the ease of better understanding, the researcher has presented the information of percentage under three headings (Agree/High, Neither Agree Nor Disagree/Moderate, and Disagree/Low). Several judgments are being made from the responses of the employees of Mercantile Bank Ltd. to validate the objectives of the study. The results are presented below.

The study finds that SMEs are not preparing proper financial statement which creates problem for the bank in judging financial standings, agree), profitability and credibility (Figure 1).

It is also observed thaty SMEs are not maintaining proper licensing (Figure 2). 
Figure 1: SMEs prepare proper financial statement

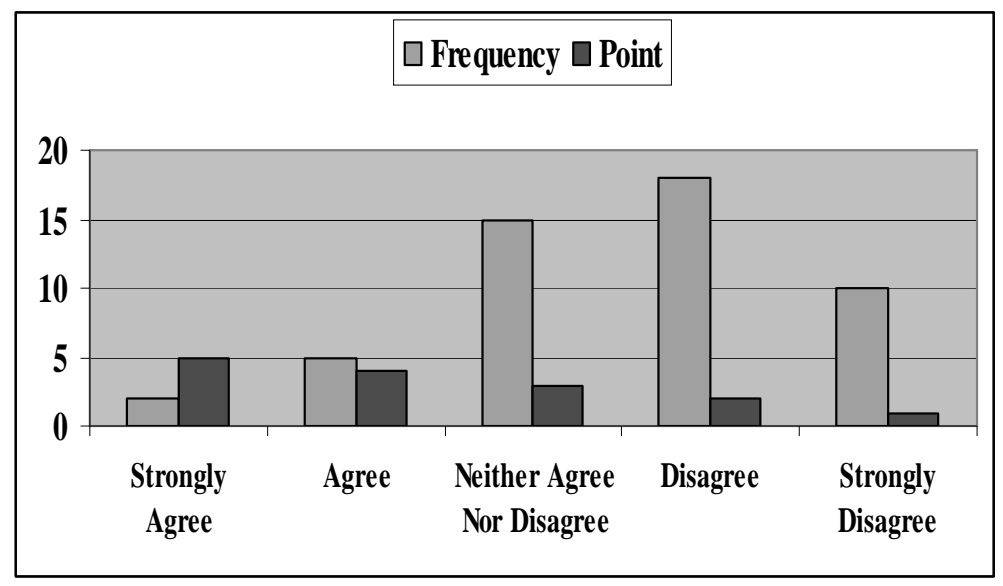

Figure -2: SMEs maintain proper licensing

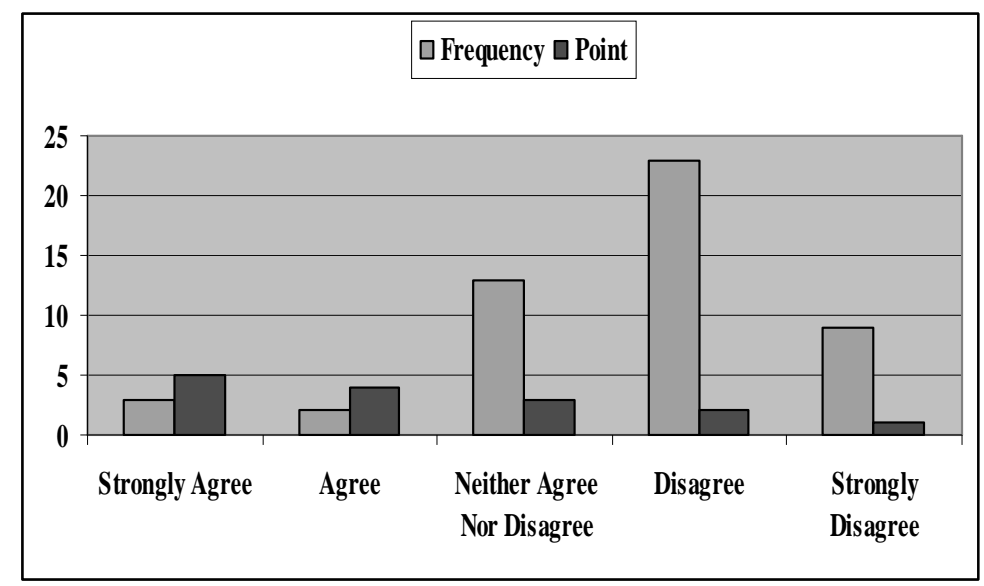

Bank employees were asked whether lack of upgraded technology affects SMEs ability to repay loans. From Figure 3 it is observed that Upgraded technology has high affects on SMEs ability to repay loans (Figure 3).

From the findings mentioned in Figure 4 it is clearly evident that Mercantile Bank Limited does not grant large loan for the SMEs. 
Figure -3: Responses on affects on SMEs ability to repay loans for Upgraded technology

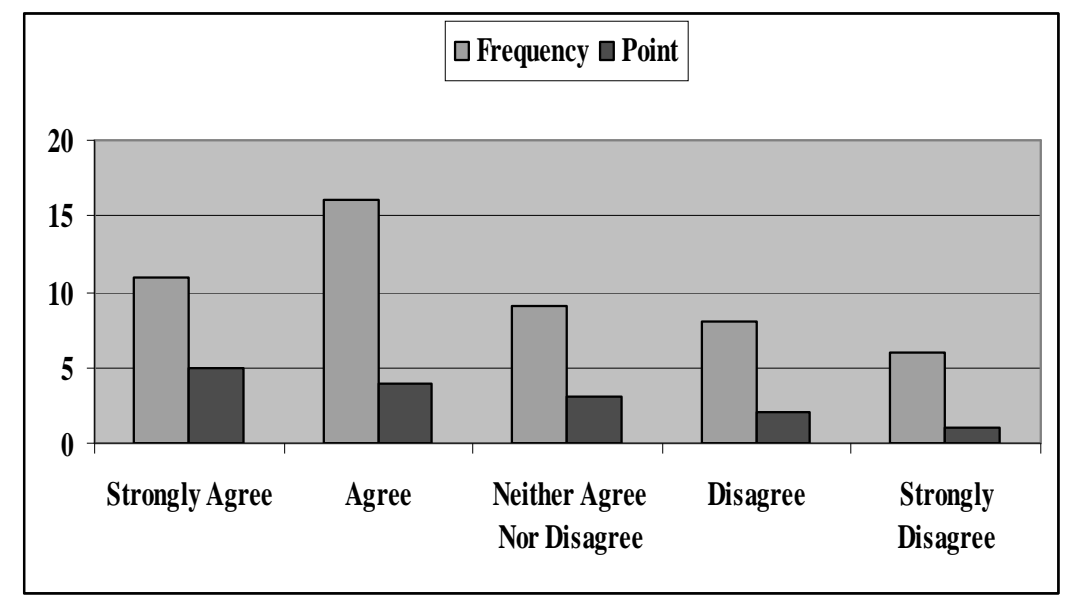

Figure -4: Mercantile Bank Limited grant large loan for the SMEs

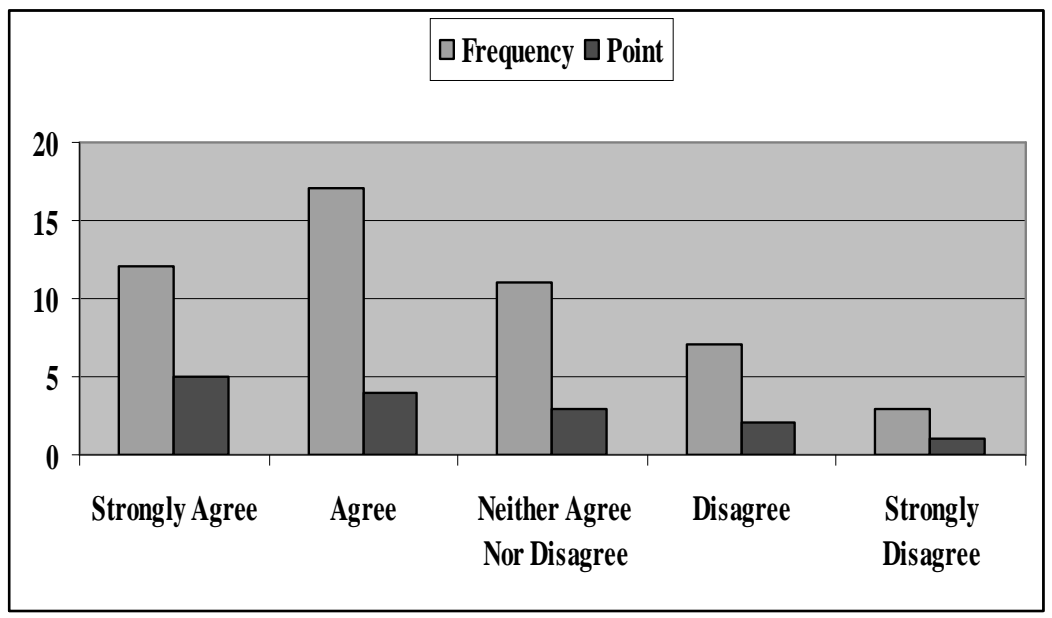

Figure 5 reveals that twenty one respondents strongly agree that MBL will get advantages it it grants loan cluster wise while only one respondent strongly disagree on this. From figure 6 it is revealed that MBL highly considers that promotional measures are needed for the products like over draft and time loan. 
Figure -5: Responses on granting loan as cluster wise

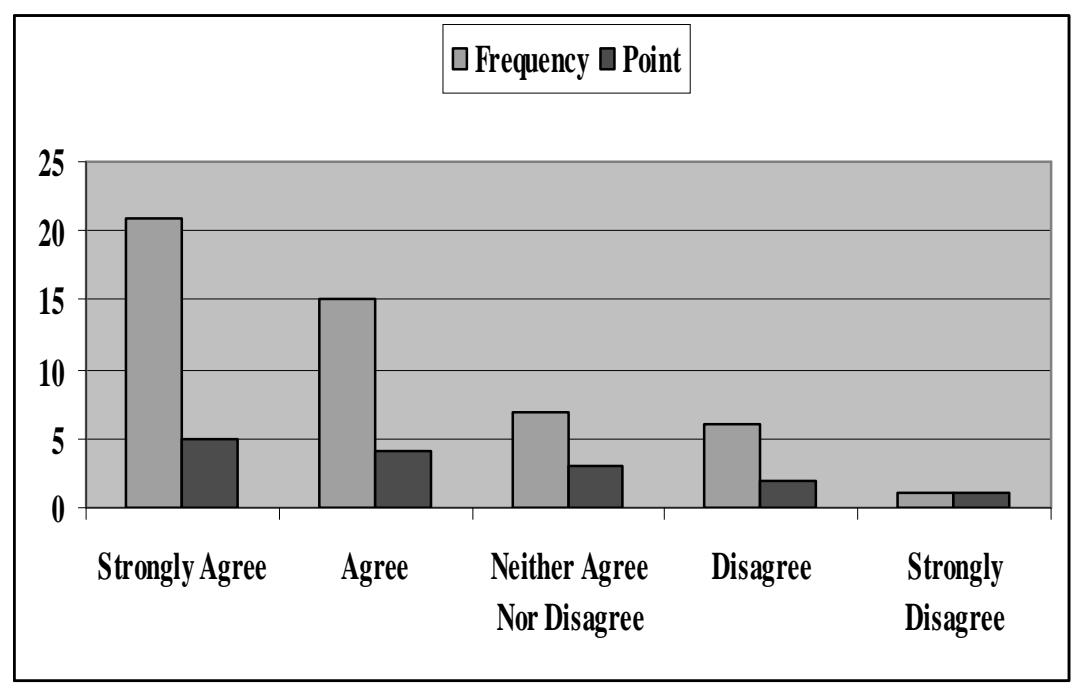

Figure -6: Responses on consideration of MBL for promotion of the products

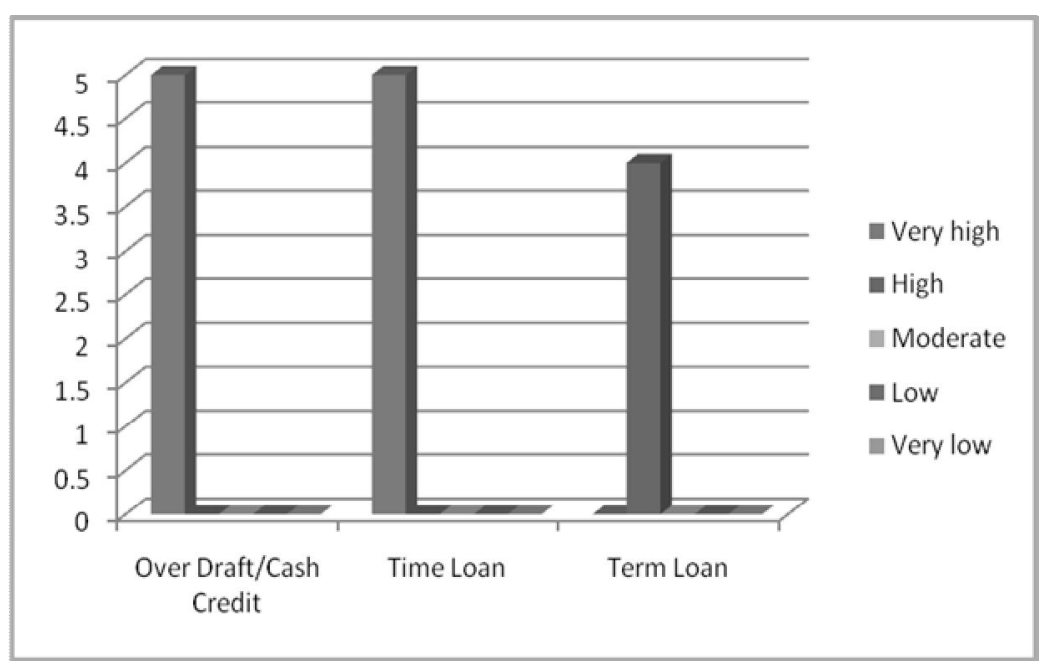


Bank employees were asked whether they consider informal loan providers as your competitor. From Table 1 it is clearly observed that Here MBL does not consider informal loan providers as its competitor.

\begin{tabular}{|c|c|c|}
\hline Items & Yes & No \\
\hline Consider informal loan providers as your competitor & Yes & $\checkmark \quad$ No \\
\hline
\end{tabular}

Respondents were asked what are the main reasons why they are not yet able to design such products (from the perspective of SMEs) for them. From Figure 7 it reveals that Bank is not yet able to design appropriate financial products for SME segment due to higher level of lack of importance, lack of trust and very high level of lack of feedback from the SME owners.

Figure -7: Responses on the ability to design appropriate financial products for SME segment

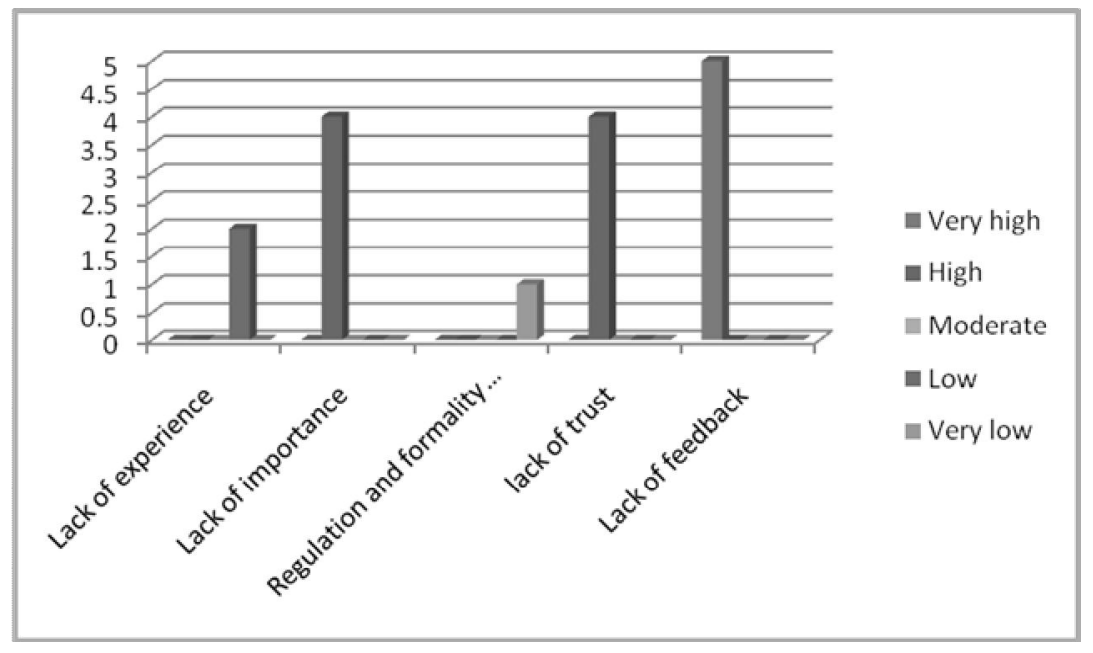

Figure 8 indicates that shorter-term loans, interconnection between individual and SME loans, accurate credit rating information have very high affect while offering lower interest rates, greater SME market research have high affect that will improve the quality of SME loan offering. 
Figure -8: Responses on factors that can improve the quality of SME loan offering

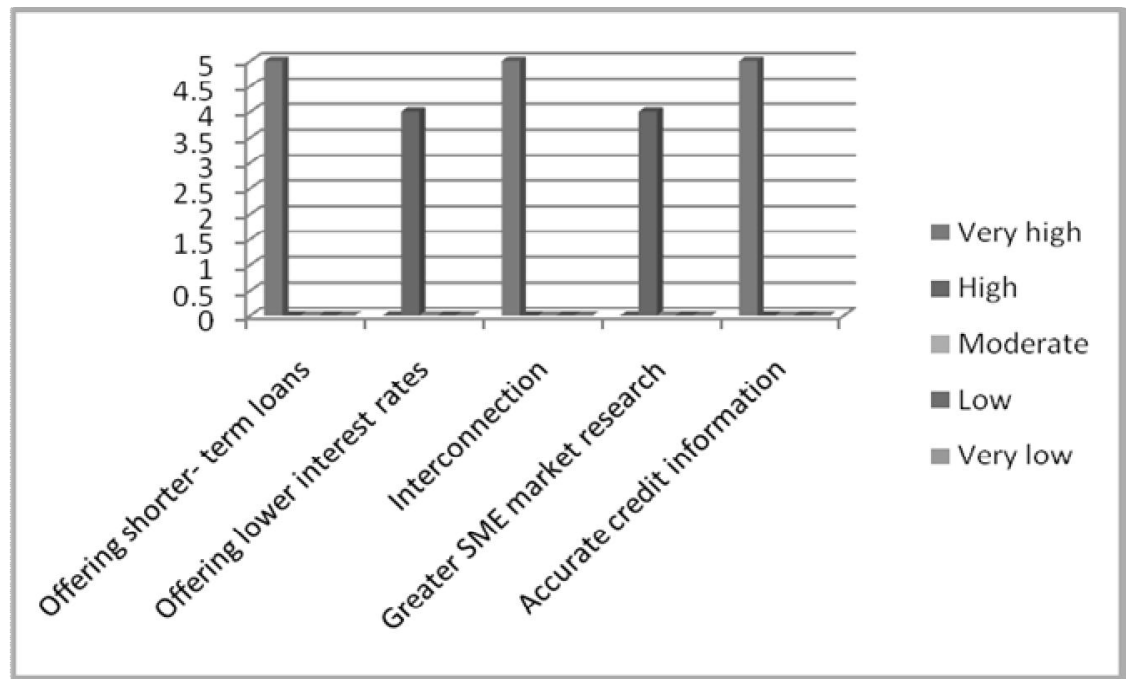

\section{HYPOTHESES TESTING}

Data were analyzed with a likert type 5-point scale ranging from strongly disagreed (1) to strongly agreed (5). In this study weighted average value of 3.5 has been considered as the optimum level for every case. $\mathrm{Z}$ test is done to test hypotheses 1-5.

Null hypothesis in hypothesis 1 stated that SMEs do not prepare proper financial statement. However, the null hypothesis is supported as the calculated $\mathrm{z}$ value $(-1.08)$ is more than the tabulated value $(-1.64)$. That is SMEs do not prepare proper financial statement.

Hypothesis 2 stated that SMEs do not maintain proper licensing. This is also supported as the calculated Z-value $(-1.16)$ is more than the tabulated value $(-1.64)$. So, it can be said that SMEs do not maintain proper licensing.

TABLE 1

\section{HYPOTHESIS 1}

\begin{tabular}{c|c|c|c}
\hline Confidence level & $\mathrm{Z}$ value & $\mathrm{Z}$ observed value & Decision \\
\hline $95 \%$ & -1.64 & -1.08 & $\begin{array}{c}\text { Null hypothesis is } \\
\text { accepted }\end{array}$ \\
\hline
\end{tabular}


TABLE 2

HYPOTHESIS 2

\begin{tabular}{c|c|c|c}
\hline Confidence level & Z value & Z observed value & Decision \\
\hline $95 \%$ & -1.64 & -1.16 & Null hypothesis is accepted \\
\hline
\end{tabular}

Hypothesis 3 predicted that Lack of upgraded technology affects SMEs ability to repay loans. This hypothesis is supported as the calculated Z-value $(-1.18)$ is more than the tabulated value (-1.64), suggesting that lack of upgraded technology affects SMEs ability to repay loans.

Hypothesis 4 stated that Mercantile Bank Limited grants large loan for the SMEs. This hypothesis is not significant as the calculated value (0.06) is less than the tabulated value (1.64). Thus it appears that Mercantile Bank Limited does not grant large loan for the SMEs.

TABLE 3

HYPOTHESIS 3

\begin{tabular}{c|c|c|c}
\hline Confidence level & Z value & Z observed value & Decision \\
\hline $95 \%$ & -1.64 & -1.18 & $\begin{array}{c}\text { Null hypothesis is } \\
\text { accepted }\end{array}$ \\
\hline
\end{tabular}

TABLE 4

HYPOTHESIS 4

\begin{tabular}{c|c|c|c}
\hline Confidence level & Z value & Z observed value & Decision \\
\hline $95 \%$ & 1.64 & 0.06 & $\begin{array}{c}\text { Null hypothesis is } \\
\text { rejected }\end{array}$ \\
\hline
\end{tabular}

Hypothesis 5 posited that Cost of operation for the bank will go down, if the bank grants SME loan cluster wise. This hypothesis is not also significant as the calculated value (0.48) is less than the tabulated value (1.64), suggesting cost of operation for the bank will not go down, if the bank grants SME loan cluster wise.

TABLE 5

HYPOTHESIS 5

\begin{tabular}{c|c|c|c}
\hline Confidence level & Z value & Z observed value & Decision \\
\hline $95 \%$ & 1.64 & 0.48 & $\begin{array}{c}\text { Null hypothesis is } \\
\text { rejected }\end{array}$ \\
\hline
\end{tabular}




\section{RESEARCH FINDINGS}

There are various problems and prospects that are associated with SME loan management. The findings of the analysis and interpretations are as follows:

1. SMEs are not preparing proper financial statement which creates problem for the bank judging financial standings, profitability and credibility.

2. SMEs are not maintaining proper licensing which makes SMEs difficult to trace, create problem for the bank maintaining records, and decrease SMEs credibility to the bankers.

3. Upgraded technology affects SMEs ability to repay loans.

4. MBL considers promotion for the product like Over Draft, Time Loan, and Term Loan to be adequate in SMEs sector.

5. Payback period suggested by banker is 1-3 years.

6. Bank does not consider informal loan providers as its competitors.

7. Bank is ready to grant loan to SMEs as a cluster.

8. Banks can trace SMEs better, can lower their cost of capital, and can give efficient service if they grant loan cluster wise.

9. Bank is not yet able to design appropriate financial products for SME segment due to lack of importance and lack of feedback from SME owners.

10. Shorter-term loans and lower interest rates will improve the quality of SME loan offering.

11. Bank improves current SME offering through interconnection between individual and SME loans so that higher amounts can be extracted.

12. Accurate credit rating information will improve the quality of SME loan offering.

\section{CONCLUSIONS AND RECOMMENDATIONS}

The SME sector in many developing countries has usually been neglected and discriminated against in terms of access to government attention, access to finance, management and marketing expertise and technology, as compared with large enterprises. SMEs in Bangladesh contribute significantly to manufacturing growth and employment creation. There are around 27,000 medium sized enterprises and around 150,000 small-scale enterprises in the country. At present, 80 percent of manufacturing establishments are SMEs, accounting for 80 percent of the labor force, 50 percent of the output of the sector and 5 percent of GDP. SMEs provide vital linkages to larger enterprises, particularly in the high-growth export sector, and also form part of the core business activities in both rural and urban areas. The 
objectives of the study are fulfilled despite some limitations. The problems are identified in this paper through detailed analysis of collected data. On the other hand the problems that MBL faced in designing proper financial products for SMEs are also identified. At the end, this study has tried to offer some suggestions to overcome those problems. If the problems can be solved the transaction between SMEs and Mercantile Bank Limited will be increased.

\section{Recommendations}

- As the SMEs in Bangladesh are habituated to operating in a semi-formal manner and banks are probably one of the most formalized institutions in our country, a big gap has opened up. The first step for Mercantile Bank Limited would be to minimize this gap by relaxing bank procedures.

- The bank should develop an official credit-rating system in easier way, even if in a limited manner, as soon as possible so that they can have some idea about the reliability of their SME clients.

- As mentioned earlier, the banks consider the credit rating system vital to their dealing with the broader SMEs. As bank like MBL already has that structure and other banks have the same clients dealing in other types of loans, the banks can greatly benefit themselves if they cooperate within themselves regarding credit rating and previous history.

- The public commercial banks and Bangladesh Bank also have SME funds or separate SME sectors, but, according to the private banks, these are considered highly inefficient and corrupted. In fact, their practice of corruption has actually affected the loan structure of private banks. As such, the private or commercial banks require urgent cooperation with the government and public banks to decide on a uniform loan structure.

- There is some unhealthy competition among the private banks regarding SME loans. Unfortunately, this has not been happening in a perfectly legal manner either. This is happened due to loan structure differences between these banks which are being exploited negatively.

- Except for some public banks, most of the commercial banks operating on the SME sector are novices and have little knowledge of the market. As a banker said, they are learning by mistakes. One way they can significantly climb up the learning curve would be through market research. For effective market research, MBL needs to work together with other banks. 


\section{REFERENCES}

Akterujjaman, S. M. and S. M. M. Islam. 2010. "Marketing Channel and Pricing of Mangoes from Chapai Nawabganj to Dhaka Retail Market." Journal of Business and Technology (Dhaka), 5(1): 125.

Alam, M. J. and Meher.Neger. 2009. "Measuring Consumer Attitude towards Beautification Products: A Study on Some Selected Brands in Bangladesh." Journal of Business and Technology (Dhaka), 4(2): 61.

Alam, M. S. and M. A.Ullah. 2006. "SMEs in Bangladesh and Their Financing: An Analysis and Some Recommendations." The Cost and Management, 34(3):57-72.

Berger, A. N. and G. E. Udell. 2005. "A More Complete Conceptual Framework for Financing of Small and Medium Enterprises." Policy Research Working Paper4481. The World Bank, pp. 1-30.

Bhattacharya, D. and T.Chowdhury. 2003. "Financial Sector Reforms in Bangladesh: The Next Round (Paper 22)." Centre for Policy Dialogue, Dhaka, p. 06.

Dhungana, B. P. 2007. "Strengthening the Competitiveness of Small and Medium Enterprises." In The Globalization Process: Prospects and Challenges.

Hoassain, N. 1998. "Contribution to SME Development in Bangladesh.” Job Opportunities and Business Support (JOBS), Banani, Dhaka, p. 27.

International Finance Corporation. 2004. "Annual Review: Small Business Activities," World Bank Group, p. 10.

Mahmud, W. 2006. "Local Business Dynamics: Ground Realities and Policy Challenges." Institutional Reform and the Informal Sector (IRIS), Dhaka, p. 13.

Malhotra, N. K. 2005. "Marketing Research: An Applied Orientation." $4^{\text {th }}$ edition. India: Pearson Education.

Mercantile Bank Limited.n.d. A Handbook of Operational Guidelines for Small Enterprise Loan Scheme - Mercantile Bank Limited.

Mercantile Bank Limited. Annual Reports of 2006, 2007, 2008 and 2009. Mercantile Bank Limited.

Moazzem K. 2006. "Meeting the Challenges in SME Development in Bangladesh: Special Reference to Government's Budgetary Measures." KATALYST, Dhaka: Bangladesh.

OECD. 2009. "The Impact of the Global Crisis on SME and Entrepreneurship Financing and Policy Responses.” Centre for Entrepreneurship, SMEs and Local Development, p. 5

Quader, M. S. and R. I. Ahmed. 2005. "The Strategic Implication of Electronic Commerce for Small and Medium Sized Enterprises (SMEs)." BRAC University Journal, II (2): 73-92.

Raymond, V. L. and E. F. Marie. 2002. Basic Business Communication, $9^{\text {th }}$ edition, New Delhi: Tata McGraw-Hill Publishing Company Limited. 
Rosen, H. 2003. "Improved Access to Finance: A Key to SME Growth.” World Bank Institute.

Siddiquee, M. M., K. M. Z Islam. and M. I.Rahman. 2006. "Revisiting SME Financing in Bangladesh." Daffodil International University Journal of Business and Economics, 1(1): 15.

Stephanou, C. and C. Rodriguez. 2008. "Bank Financing to Small and Medium-Sized Enterprises (SMEs) in Colombia." Policy Research Working Paper-4481. The World Bank, pp. 1-44.

The Daily Star Editorial, $16^{\text {th }}$ July 2006, Dhaka. 